\title{
A POESIA E A FAMÍlIA: RELATO DE EXPERIÊNCIA
}

\author{
Ivone Gomes de Santana Moura* \\ Leonora Alves da Cunha ${ }^{*}$
}

\begin{abstract}
Resumo
Este artigo é resultado de um projeto de pesquisa que tem, dentre outros, o objetivo de construir uma proposta preventiva sobre o uso de drogas pautado no diálogo com as famílias, utilizando como meio de sensibilizaçáo o texto poético. Buscaram-se, por meio deste diálogo, momentos de reflexão sobre a aprendizagem caminhando por vias poéticas, com músicas e poemas sob o olhar dos serviços sociais, em interface com a educação.

Palavras-Chave: escola, família, aprendizagem, poesia, drogas.
\end{abstract}

The poetry and the family: one experience

Abstract

This article is the result of a research that aims at constructing a preventive proposal about the drug's use based on the dialogue with students' families, using the poetic text as a way of sensibilization. We tried through dialogue, moments of reflection on learning, following a poetic path, such as music and poetry, under view of the social's services in interface with the education.

KEY wORDs: school, family, learning, poetry, drugs.

A escola é um campo propício de atuação para açóes preventivas por expressar, em seu cotidiano, as múltiplas contradições das desigualdades sociais, uma vez que é neste ambiente que estão presentes estudantes e famílias com as mais diferenciadas experiências, vivenciadas nas relaçóes sociais capitalistas.

As desigualdades aparecem nitidamente nos discursos das crianças, dos adolescentes e das famílias que fazem parte do cotidiano do Centro de Ensino e Pesquisa Aplicada à Educação da Universidade Federal de Goiás (Cepae/UFG), ao afirmarem o desconhecimento dos seus direitos, deveres e, até mesmo, do acesso aos bens culturais públicos. Corrobora, ainda,

* Assistente Social do Cepae e especialista em Serviço Social e movimentos sociais. Email: ivemoura@hotmail.com.

** Técnica em Arquivo do Cepae e especialista em Administração Escolar e Planejamento Educacional. E-mail: leoalvescunha@bol.com.br. 
com esta situação, a forma de acesso a esta escola, realizada por meio do sorteio de vagas. Assim, em um universo de diferentes condiçóes sociais, econômicas e culturais são sorteados os alunos que compóem o corpo discente da escola. Esta variedade se torna um desafio para os diversos profissionais que trabalham nesta instituição, exigindo deles um olhar sensível para a pluralidade que lhes é apresentada.

Nesse contexto faz-se necessário perceber a criança e o adolescente como ser humano em formação, que vive, pensa e ama. Portanto, há que vê-los na sua intimidade, saber lidar com suas emoçôes, frustrações, debilidades, contornar situaçóes para que seu mundo tenha sentido. É, pois, fundamental a inserção da poesia no cotidiano das famílias para que o ser humano se perceba em sua essência, constituindo-se em sujeito de suas ações e tomando suas próprias decisóes sobre a vida.

Sendo assim, um contato permanente com os estudantes e, também, com suas famílias, buscando apreender suas realidades e apresentando estratégias mais democráticas para a prestação de serviços requer ações voltadas ao "fortalecimento dos sujeitos coletivos, dos direitos sociais, e a necessidade de organização para a sua defesa, construindo alianças com os usuários dos serviços, com suas organizaçóes, para efetivação dos mesmos" (Iamamoto, 2004, p. 273).

Moura (2000) afirma que o caminho percorrido na história do Serviço Social nessa escola para construir uma proposta fundamentada nos princípios de cidadania, inclusão social e comprometida com a qualidade dos serviços prestados foi o de propor projetos de intervençáo com os segmentos deste Centro, com outras Unidades da UFG e com Instituiçóes prestadoras de serviços, em interface com a educação. Conforme a autora (2002), atualmente, a atuação do Serviço Social no Cepae tem como princípio uma concepção dialética do Serviço Social e do seu papel social em uma equipe interdisciplinar. Para tanto, o trabalho tem se pautado, ao longo dos anos, no mapeamento de sua realidade social a partir do eixo temático: quem são os usuários do Cepae e quais as suas expectativas em relação a este Centro.

Assim, mediante as expectativas de estudantes e adolescentes sobre alguns serviços que poderiam fazer interface com a educação e que eles gostariam que esta escola lhes oferecesse, em 2004 foi aberto um diálogo com a Coordenação do programa Saudavelmente, da Equipe de Saúde Mental da Pró-reitoria da UFG. Como resultado desse diálogo foi proposto um 
estudo sobre o uso de drogas e a construção de uma proposta de prevenção para o Cepae/UFG (Silva et al., 2004).

Em 2005 a escola, em conjunto com o Serviço de Psicologia do Departamento de Saúde Mental e Medicina Legal da Faculdade de Medicina da UFG, propôs a construção de um projeto com o objetivo de viabilizar o acesso às informaçóes sobre as questôes da infância e da adolescência para as famílias. Ao discutir que as escolas podem desenvolver programas de prevenção, por meio de investigação de jovens em risco, e criar espaços no contexto escolar para que a família ocupe um lugar de parceira na prevenção destas situações, se idealizaram ações que resultaram no artigo "Escola como espaço de prevenção às situações de risco: relato de experiência" (Teixeira et al., 2006).

Haja vista as especificidades dos estudantes do Cepae e de suas famílias em relação à incidência e prevalência do uso de drogas, as situações de risco com substâncias psicoativas, as sugestóes apresentadas para resolver a questão do uso e as expectativas da comunidade do Cepae em relaçáo a essa questão social, em 2006 foi proposto o projeto "Serviço Social e família: um diálogo sobre aprendizagem" (Moura, 2006), com a participação de pais, mães ou responsáveis pelas crianças e adolescentes da instituição.

Para tanto, buscou-se atender o interesse imediato e específico dos professores que têm como objetivo trabalhar as dificuldades dos estudantes no processo de escolarização; propôs-se um diálogo com as famílias para que tivessem acesso às informaçóes sobre aprendizagem, cidadania, saúde e uso de substâncias químicas e pudessem fazer uso dos serviços sociais, em interface com a educação, existentes na UFG e em outras instituiçôes.

Foram, então, realizados encontros mensais, que aconteceram de agosto a novembro de 2006, para abordar os temas: formas de aprender e as condiçóes que favorecem ou inibem o processo de aprendizagem; escola e cidadania; a saúde escolar e o processo de aprendizagem; e o uso de substâncias químicas e o processo de aprendizagem.

A dinâmica utilizada nos encontros buscou dar ênfase aos interesses do grupo, com uma estratégia de intervenção fundamentada na perspectiva dialética, em que o conhecimento da realidade social é definido pela relação conhecimento/ação.

Assim, a ação proposta foi norteada pela discussão de temas relacionados à aprendizagem. Os recursos utilizados para as reflexóes partiram da música e da poesia, e a avaliação, ao término dos encontros, serviu para 
elucidar o significado que as famílias atribuem a esses temas, além de vislumbrar alternativas de soluçōes para o processo de aprendizagem formal, dentro da própria família ou escola e em outras instituiçóes.

As artes e, particularmente, a música e a poesia, ajudam a aflorar no homem as sutilezas da vida, devido a sua linguagem emotiva, procurando mostrar, de forma sensível, um novo olhar sobre a mesma realidade, criando possibilidades para que as pessoas envolvidas no processo possam refletir sobre suas açốes e condutas para, a partir de então, transformar-se. Devido a esse pensamento, abordamos de forma interdisciplinar os serviços sociais em interface com a educação, caminhando por vias poéticas.

Para os encontros, escolhemos poesias que trouxessem mensagens altruístas, fizessem refletir sobre o sentido da vida, tivessem uma orientação positiva diante da realidade, além de contribuírem para uma transformação interior, ou seja, elevarem a consciência dos participantes, como, por exemplo, a poesia "Operário em construção", de Vinícius de Moraes (2006):

[...] Foi dentro da compreensão / desse instante solitário / que, tal sua construçáo / cresceu também o operário. / Cresceu em alto e profundo / em largo e no coração / e como tudo que cresce / ele nấo cresceu em vão, / pois além do que sabia / - exercer a profissão - / o operário adquiriu uma nova dimensão: / a dimensão da poesia [...].

$1^{\circ}$ encontro - Tema: Formas de aprender e as condiçóes que favorecem ou inibem o processo de aprendizagem.

Nesse encontro, ao discutir o tema proposto, o objetivo foi, também, de que cada participante colocasse suas expectativas sobre o convite da escola para participar de encontros periódicos e discutir sobre a aprendizagem. Para que isso fosse possível utilizou-se música, texto científico e poesia. $\mathrm{O}$ uso da música e do poema contribuiu para refletir sobre a proposta da escola de estar ao lado da família no processo educacional, contrapondo-se à prática de convidá-la a comparecer neste Centro apenas no momento de discutir a indisciplina, o baixo rendimento escolar ou a reprovaçáo. $\mathrm{O}$ texto possibilitou às pessoas pensarem sobre o processo de aprendizagem na situação da sala de aula, na relação professor-aluno, na relação escola-família e na produção do fracasso escolar. 
Durante a leitura desse texto os comentários livres são associados ao cotidiano da sala de aula, às dificuldades de se formar o hábito de estudo e aos ambientes inadequados para a aprendizagem. Concluiu-se que o tema abordado contribuiu para ampliar conhecimentos; definir o papel da família e da escola em relação ao processo de aprendizagem; e para esclarecer que tanto a família quanto a escola podem contribuir com a formação de idéias sobre a vida escolar, além de poderem proporcionar um ambiente adequado para a aprendizagem, respeitando a individualidade e o ritmo de cada um, dialogando, transmitindo valores de civilidade, acompanhando as tarefas escolares, incentivando a pesquisa e o uso da informática.

\section{$2^{\circ}$ encontro - Tema: Escola e cidadania.}

Para trabalhar este tema, discutiu-se em grupo a concepção de cidadania, cidadáo e escola cidadá. Para tanto, foi disponibilizado aos participantes, papel, lápis, a Lei n. 8.069/1990, que dispóe sobre o Estatuto da Criança e do Adolescente - ECA (Brasil, 1990), o Regimento Escolar (Cepae, 2003) e o Dicionário da Língua Portuguesa (Bueno, 1991).

Ao apresentar o resultado da discussáo realizada foi colocada, no quadro, a síntese dos grupos, salientando os conceitos trabalhados. Assim, concluiu-se que, segundo o dicionário da língua portuguesa em 1991, cidadania é a qualidade ou nacionalidade de cidadão que, por sua vez, significa habitante da cidade, indivíduo no gozo dos direitos civis e políticos de um Estado. Atualmente, a cidadania está relacionada à democracia, à autonomia, aos direitos, deveres e acesso a serviços sociais nas áreas de saúde, educação, assistência e previdência, habitação, infância, adolescência, idosos, entre outros.

Foi observado, também, que o exercício da cidadania se corrompe quando atende apenas a interesses individuais, ou quando as pessoas desconhecem seus direitos e deveres; uma escola cidadã deve valorizar os educadores, os estudantes, ser criativa, organizada, ouvir o estudante, a família e ser capaz de solucionar conflitos que possam surgir durante o desenvolvimento da criança e do adolescente. Participar do processo educacional dos filhos acompanhando-os na sua vida escolar é um exemplo de ação, nos dias atuais, para exercitar a cidadania.

Para concluir o tema, as concepções do grupo foram relacionadas com as conquistas contidas no ECA, em que crianças e adolescentes são 
concebidos como pessoas em situação peculiar de desenvolvimento e portadoras de direitos. Em seguida ouviu-se o poema "O operário em construção" (Moraes, 2006) que narra, em versos, o papel do operário na construção das coisas, o desconhecimento da importância de sua profissão e a alienação de seu trabalho. Comenta-se sobre os ideais, a importância da família e da escola e a edificação coletiva para alcançar o objetivo de formar um aluno cidadão.

$3^{\mathbf{o}}$ encontro - Tema: A saúde escolar e o processo de aprendizagem

Para incentivar a reflexão sobre a saúde escolar e o processo de aprendizagem o grupo recebeu a primeira parte do texto "O espelho do futuro: uma história que poderia ser a sua" (Cury, 2006), que fala de um aluno agressivo, que zombava dos colegas mais tímidos, e como essas atitudes levaram um estudante da sala a várias doenças e à perda da esperança de viver. Como a família não tinha um diálogo aberto não percebia sua intensa dor, que este expressava ao dizer que queria mudar de escola.

Após leitura em conjunto foi discutida a concepção de dificuldade de aprendizagem, de dificuldade escolar e de saúde. As conclusóes foram colocadas no quadro, procurando distinguir a diferença entre dificuldade de aprendizagem e dificuldade escolar.

Suas opinióes sobre dificuldades escolares referiam-se ao ensino fraco, ao obstáculo no desenvolvimento da relação professor-aluno, a falta de estímulo em casa, as doenças, ao desequilíbrio emocional e a ausência da família nas reuniōes escolares. As dificuldades de aprendizagem foram expressas com exemplos de crianças que não aprendem matemática, leitura, escrita, escrevem com letra feia, fazem leitura, mas não entendem. A saúde foi pensada como ausência de doença, relacionada à alimentação saudável, ao apoio emocional, à educação e à moradia de qualidade.

Para concluir a discussão, salientou-se a diferença entre os conceitos de dificuldades escolares e de aprendizagem, fez-se um breve histórico da saúde do sistema escolar no Brasil, envolvendo o conceito de saúde, as dificuldades de aprendizagem que a criança pode apresentar, o significado do estigma como resultado de um julgamento ingênuo, o direito à saúde, contido no ECA, e como fazer uso destes direitos por meio dos serviços de proteção à saúde da criança e do adolescente, disponibilizados no Cepae, na UFG e no Sistema Único de Saúde (SUS). 
$\mathrm{Na}$ opinião do grupo, esse encontro atendeu totalmente às suas expectativas, contribuindo para definir o papel da família e da escola em relação à saúde escolar e ao processo de aprendizagem. Fazer acompanhamento da saúde; observar o desenvolvimento escolar do aluno; participar mais de reunióes na escola e oferecer oficinas de teatro são sugestôes de atividades apresentadas à família e à escola para contribuir com o processo de aprendizagem das crianças e adolescentes do Cepae que possam apresentar dificuldades escolares ou de aprendizagem.

$4^{\mathbf{o}}$ encontro - Tema: $\mathrm{O}$ uso de substâncias químicas e o processo de aprendizagem.

Para estimular a discussão sobre drogas na escola e o papel do Cepae, da UFG e da família na prevenção, foi realizada uma leitura do texto "Drogas" (Michelin, 2006).

Após a leitura foram apresentadas e comentadas as ações realizadas pela pesquisa "Um estudo sobre o uso de drogas e a construçáo de uma proposta de prevenção para o Cepae/UFG” (Silva et al., 2004).

Por último, para encerrar os questionamentos levantados durante a apresentação da pesquisa, buscamos as opinióes do grupo sobre experimentação, uso e abuso de substâncias químicas e concluímos que no contexto da Universidade essa questão tem sido tema de discussóes. O Cepae, sendo parte da Universidade e constituído por seres humanos de diversas faixas etárias, não está isento dessa questão social.

A assistente social acrescentou que o ECA trata da proteção integral da criança e do adolescente como dever geral da família, da comunidade, da sociedade em geral e do poder público, assegurando com absoluta prioridade a efetivação dos direitos referentes à vida, à saúde, à alimentação, à educação, ao esporte, ao lazer, à profissionalização, à cultura, à dignidade, ao respeito, à liberdade e à convivência familiar e comunitária.

Informou, ainda, que a Universidade Federal de Goiás possui um programa, o Saudavelmente, que realiza atendimento psicossocial e médico-psiquiátrico para a comunidade universitária, abordando a saúde e a vida. Para tanto oferece terapias individuais, em grupo e familiar, além de encaminhamentos para tratamentos em clínicas especializadas ou centros de recuperação de pessoas que abusam de substâncias psicoativas. No Cepae as açōes de prevenção, até então, têm promovido encontros com as 
famílias para abordar questóes de educação, informar sobre os programas disponíveis, democratizar e acompanhar o acesso a esses programas.

Por outro lado concluiu-se que, ao pensar o uso de drogas como questáo social, pode-se afirmar que o abuso é resultado de várias condições de vida e que a sociedade nos oferece riscos e proteção. Diante desse contexto, tanto a família quanto a escola, como instituiçôes educadoras, podem se constituir em risco ou em proteção para o uso de substâncias psicoativas.

Como condiçóes de proteção da família, o grupo relaciona acompanhar as atividades dos filhos, além de estabelecer regras e condutas claras e respeito à individualidade. Já a escola tem como condiçôes de proteção possibilidades que proporcionam aos estudantes e suas famílias descobertas pessoais, prazer em aprender, em construir projetos de vida, vínculos afetivos com colegas, professores e técnicos administrativos.

Em seguida, os participantes receberam material com informaçôes sobre os efeitos e riscos do abuso, os sinais comuns deste e o que fazer ao deparar-se com pessoas nessas condições; preencheram uma avaliação do projeto, assinalando se ele atendeu às suas expectativas, apontando para a sua continuidade, no próximo ano, e sugerindo temas referentes à adolescência, à aprendizagem e ao uso de drogas. Para encerrar o grupo em 2006, com o objetivo de continuidade em 2007, apresentou-se, em power point, o texto "Ainda tomaremos um café juntos" (autor desconhecido), que relata a história de um professor de filosofia que procura demonstrar a sua classe que as pessoas podem estar repletas de felicidade se os elementos mais importantes de suas vidas forem Deus, a família e os amigos.

\section{Consideraçóes Finais}

Ao refletir sobre a relação que está se construindo com outras Unidades da UFG, para que estudantes e famílias do Cepae tenham acesso aos serviços de saúde em interface com a educação, pode-se concluir que o caminho percorrido busca a mobilização das condições objetivas da realidade.

Em relação aos desafios enfrentados, vale ressaltar que as questôes sociais exigem, de um lado, profissionais capazes de potencializar intervençôes por meio da pesquisa e de açóes diretas, "[...] estimuladora da participação dos sujeitos nas decisóes que lhes dizem respeito, na defesa 
de seus direitos e no acesso aos meios de exercê-los" (Iamamoto, 2004, p. 295). Por outro lado, é necessária uma visão crítica das questôes sociais, que coloque as políticas sociais como primazia do Estado, pois o protagonismo escolar pressupóe organizar-se a partir da construção de "espaços que promovam a prática política, da explicitação das dúvidas e negociação de interesses e desejos" (Ricci, 2002, p. 6).

\section{REFERÊNCIAS}

BRASIL. Secretaria de Cidadania. Secretaria Especial dos Direitos Humanos da Presidência da República. Lei Federal 8.069/1990. In: Estatuto da Criança e do Adolescente. Goiânia: CEDCA-GO, 2006.

BUENO, F. S. Minidicionário da Lingua Portuguesa. São Paulo: Lisa, 1991.

CEPAE. PROGRAD. UFG. Regimento aprovado em reunião do Conselho Diretor de 17/03/2003.

CURY, A. Filhos brilhantes alunos fascinantes. Rio de Janeiro: Sextante, 2006.

IAMAMOTO, M. V. Questão social, família e juventude: desafios do trabalho do assistente social na área sociojurídica. In: SALES, M. A; MATOS, M. C. e LEAL, M. (Orgs.) Politica Social, Familia e Juventude: uma questão de direitos. São Paulo: Cortez, 2004. p. 261-298.

MORAES, V. O operário em construção. Disponível em: < www.viniciusdemoraes.com.br > Acesso em: 05 de nov. de 2006.

MOURA, I. G. S. A construção da proposta do Serviço Social no Cepae/ UFG. Fragmentos de Cultura. v.10, n. 4, p. 785-808, jul./ago. 2000.

O questionário socioeconômico-cultural como instrumento para formulação de políticas sociais. Solta a Voz, Goiânia, v. 1, n. 2, p. 72-79, jan./dez., 2002.

Projeto de Intervenção. Serviço Social e família: um diálogo sobre aprendizagem. Aprovado no Conselho Diretor do Cepae em 2006.

RICCI, R. O protagonismo juvenil e a crise das instituiçôes modernas. Disponível em: < www.portalccp.com.br > Acesso em: 29 de mar. de 2007. 
206 Revista Solta a Voz, v. 18, n. 2

SILVA, C. G. et al. Projeto de pesquisa: um estudo sobre o uso de drogas e a construção de uma proposta de prevenção para o Cepae/UFG. Aprovado no Comitê de Ética em Pesquisa/UFG, Goiânia, 2004.

TEIXEIRA, C. M. F. S. et al. Escola como espaço de prevenção às situaçóes de risco: relato de Experiência. Solta a Voz, Goiânia, n. 2, p. 92-102, jul./dez., 2006.

Recebido em: 29 jun. 2007

Aceito em: 26 out. 2007 